\title{
Alterations in NK Cell Phenotype in Relation to Liver Steatosis in Children with Chronic Hepatitis C
}

\author{
Anna Mania,, ${ }^{1,6}$ Mariusz Kaczmarek, ${ }^{2}$ Pawel Kemnitz, ${ }^{1}$ Iwona Mozer-Lisewska, ${ }^{3}$ Jan Sikora, ${ }^{2}$ \\ Magdalena Figlerowicz, ${ }^{1,4}$ Aldona Woźniak, ${ }^{5}$ Katarzyna Mazur-Melewska, ${ }^{1}$ \\ Wojciech Służewski, ${ }^{1}$ and Jan Żeromski ${ }^{2}$
}

\begin{abstract}
NK cells were found to play an important role in liver fibrosis, a process commonly seen in a chronic liver disease such as chronic hepatitis $\mathrm{C}$ (CHC). The aim of this study was to evaluate potential differences in relation to coexisting liver steatosis in children with chronic hepatitis $\mathrm{C}$. The study group consisted of 31 children with chronic hepatitis, aged $7-18$ years (mean $=15 \pm 2$ years). Blood samples were taken prior to liver biopsy. The METAVIR scale was used for histological evaluation. Peripheral lymphocytes were subjected to monoclonal antibodies to CD56 antigen, KIRs and NKG2D antigens. Cells were assayed by flow cytometry for the ratio of positive cells and mean fluorescence intensity (MFI). Results were evaluated regarding the presence of liver steatosis. Significantly higher mean AST activity as well as higher AST-to-platelets ratio index (APRI) was observed in a group of children with coexisting liver steatosis. These children had significantly higher MFI for CD158e and lower MFI for NKG2D. All CHC patients had significantly higher MFI for NKG2D than the controls. The proportion of cells with expression of CD158i, KIR2D and APRI was found independent predictors of liver steatosis in univariate analysis and body mass index in logistic regression. The expression of NK cell receptors is altered in coexisting steatosis that may influence long-term prognosis in CHC.
\end{abstract}

KEY WORDS: chronic hepatitis C; children; NK cell receptors; liver fibrosis; liver steatosis.

\section{INTRODUCTION}

Infection with hepatitis $\mathrm{C}$ virus (HCV) is still a significant health problem worldwide. HCV is capable of evading the immune response and causes chronic infection leading to significant consequences such as liver cirrhosis and hepatocellular carcinoma. Although

\footnotetext{
${ }^{1}$ Department of Infectious Diseases and Child Neurology, University of Medical Sciences, ul. Szpitalna 27/33, 60-572 Poznań, Poland

${ }^{2}$ Chair and Department of Clinical Immunology, University of Medical Sciences, Poznań, Poland

${ }^{3}$ Department of Infectious Diseases, University of Medical Sciences, Poznań, Poland

${ }^{4}$ Higher Vocational State School of Stanisław Wojciechowski, Kalisz, Poland

${ }^{5}$ Chair of Clinical Pathology, University of Medical Sciences, Poznan, Poland

${ }^{6}$ To whom correspondence should be addressed at Department of Infectious Diseases and Child Neurology, University of Medical Sciences, ul. Szpitalna 27/33, 60-572 Poznań, Poland. E-mail: mania@mp.pl
}

the clinical course is relatively mild in childhood, $\mathrm{HCV}$ infection may lead to significant lesions in liver histology that slowly but surely progress with the duration of infection with a varied rate [1]. Inability of the host to produce an effective immune response depends on many factors including innate and acquired immunity and is particularly important in childhood due to coexisting immaturity of the immune system.

Natural killer (NK) cells belong to lymphocyte cells aiming at direct interaction with virus-infected host cells. Moreover, NK cells secrete cytokines activating T helper type 1 cells to enhance cytotoxic $\mathrm{T}$ cell response. They also activate dendritic cells [2]. Their multiple functions are controlled by activating and inhibitory receptors. Signals from the receptors are integrated to determine final possible activation. NK cells accumulate in the liver in the state of infection [3]. A recent report shows many alterations in phenotype, activity and frequency of NK cells in chronic hepatitis C (CHC) [4]. 
Major inhibitory receptors are the killer cells' immunoglobin-like receptors (KIR) and NKG2A. Key activating receptors are natural cytotoxicity receptors that also belong to the KIR family and NKG2D. Most of the inhibitory receptors recognize MHC class I and MHC class I-like molecules, while ligands of many activating receptors remain unknown. NKG2D recognizes ligands induced by cellular stress on virally infected or transformed cells [5].

Expression of NK cell receptors is altered in conditions of chronic HCV infection. They may be both up- and down-regulated in CHC. Recently, lower levels of NKG2D were described, while expression of KIR was normal or low [6].

NK cells were found to play an important role in liver fibrosis, a process commonly seen in chronic liver disease. NK cells appear to be involved in hepatic stellate cell (HSC) death; therefore, depletion of NK cells was leading to the progression of fibrosis on an animal model [7]. Liver steatosis is a well-known factor associated with the progression of liver fibrosis and was found to be an independent predictor of advanced fibrosis in $\mathrm{CHC}$ [8].

Reports regarding the issue in children, with the additional condition of a developing immune system, are scarce. The aim of this study was to evaluate potential differences in relation to coexisting liver steatosis in children with $\mathrm{CHC}$.

\section{MATERIAL AND METHODS}

The study group consisted of 31 children with CHC -17 boys and 14 girls, aged $7-18$ years (mean $=15 \pm 2$ years). The control group included 23 children without liver diseases. Chronic hepatitis C was diagnosed on the basis of standard clinical criteria. History data were taken, and all children underwent clinical examination and abdominal ultrasound scanning prior to liver biopsy. Duration of infection was estimated on the basis of past medical record counting from the moment of the appearance of the first HCV infection markers. All biopsies were taken for diagnostic purposes after obtaining informed consent from legal guardians of the patients according to local legal regulations. Blood samples were taken at the same time for standard laboratory tests. HCV-RNA level was measured using RT-PCRqualitative test AMPLICOR HCVTM (Roche), version 2.0; sensitivity level, $50 \mathrm{IU} / \mathrm{ml}$. The $\mathrm{HCV}$ genotype was established using HCVII Amplification Procedure INNO-LIPA HCV-II, Innogenetics. The liver biopsy was performed for diagnostic purposes in all children using the Menghini procedure-Hepafix kits (needles, $1.4 \mathrm{~mm}$; Braun) in sedation. The histological evaluation was performed by a pathologist blinded from history and clinical data and included inflammatory activity and fibrosis using the METAVIR scoring system. On the basis of basic laboratory parameters, the AST-to-platelets ratio index (APRI) score was calculated using the following formula: $\quad A P R I=(A S T$ level/ULN $) /$ platelet counts $\left(10^{9} / 1\right) \times 100$ [8]. Body mass index (BMI) was calculated from the formula: body weight $(\mathrm{kg}) /($ body height $(\mathrm{m}))^{2}$. Characteristics of the study group have been presented in Table 1 .

\section{Flow Cytometry}

NK cells were identified in PBMC as CD3-/ CD56+. NK cell phenotyping was performed using a blood specimen incubated with the following antibodies to inhibitory and activating receptors: CD-3 - peridininchlorophyll-protein complex (Becton Dickinson), CD56-allophycocyanin (APC), CD 158b (KIR2DL2/ DL3)-phycoerythrin (PE), CD 158e (KIR3DL1)-PE, CD158i (KIR2DS4)-PE, KIR2D-PE (Milteneyi Biotec Inc) and CD314(NKG2D)-PE (R\&D Systems). The following control antibodies were also used: mouse $\mathrm{IgG} 2 \mathrm{a}$ isotype-PE, mouse $\mathrm{IgG} 2 \mathrm{a}$ isotype-APC and mouse IgG2a-PE (Miltenyi Biotec Inc). Red cells were lysed using FACS lysing solution, and the lymphocytes were washed three times before further analysis on a FACS Canto flow cytometer (Becton Dickinson). Results were presented as the proportion of cells with expression of a particular receptor as well as mean fluorescence intensity (MFI). Isotype-matched control antibodies were used to determine background levels of staining.

The study obtained approval from the Bioethical Committee of the University of Medical Sciences in Poznań, Poland (no. 234/08 from September 4, 2008).

\section{Statistical Analysis}

Continuous variables were expressed as mean, standard deviation, median and range. Normality was checked using the Shapiro-Wilk test. Consequently, Mann-Whitney test or Student's $t$ test was used where appropriate. Categorical variables were expressed as frequency and percentage. They were compared by the 
Table 1. Characteristics of the Study Group - 31 Children with CHC

\begin{tabular}{|c|c|c|c|c|c|}
\hline Feature & Number & Percentage & $\bar{X} \pm \mathrm{SD}$ & $M$ & Range \\
\hline Age (years) & - & - & $14.94 \pm 2.46$ & 16 & $2-17$ \\
\hline Gender, male/female & $17 / 14$ & $55 / 45$ & - & & \\
\hline Age at infection (years) & - & - & $3.55 \pm 3.30$ & 3 & $0-12$ \\
\hline Duration of infection (years) & - & - & $11.39 \pm 3.68$ & 13 & $3-16$ \\
\hline Duration of infection $>10$ years, $\mathrm{Y} / \mathrm{N}$ & $22 / 9$ & $71 / 29$ & & & \\
\hline Probable route of infection: nosocomial/vertical & $28 / 2$ & $90 / 10$ & & & \\
\hline Body weight $(\mathrm{kg})$ & - & - & $59.36 \pm 14.68$ & 58.00 & $24-88$ \\
\hline Body mass index $\left(\mathrm{kg} / \mathrm{m}^{2}\right)$ & - & - & $20.94 \pm 3.79$ & 20.35 & $12.98-29.41$ \\
\hline History of childhood malignancy, Y/N & $19 / 12$ & $61 / 39$ & - & - & - \\
\hline HCV genotype $1 b / 1 a / 3 a$ & $7 / 23 / 1$ & $23 / 74 / 3$ & - & - & - \\
\hline HCV-RNA viral load (IU/ml) & - & - & $1,757,627 \pm 3,226,000$ & 367,500 & $100-14,800,000$ \\
\hline ALT (IU/l) & - & - & $71.87 \pm 95.55$ & 39 & $15-486$ \\
\hline Inflammatory activity (METAVIR) & - & - & $1.41 \pm 0.63$ & 1.00 & $1-3$ \\
\hline Fibrosis (METAVIR) & - & - & $1.55 \pm 0.87$ & 1.00 & $1-4$ \\
\hline Liver steatosis, Y/N & $12 / 19$ & $39 / 61$ & - & - & - \\
\hline APRI & - & - & $0.74 \pm 0.86$ & 0.44 & $0.19-3.48$ \\
\hline
\end{tabular}

$\bar{X}$ mean, $S D$ standard deviation, $M$ median, $A P R I$ AST-to-platelets ratio index, $Y$ yes, $N$ no

chi-square or Fisher exact test where appropriate. Comparison of multiple groups was performed using Kruskal-Wallis test. Correlations were found using Pearson correlation and Spearman test. Factors associated with liver steatosis were sought by univariate analysis and multivariate analysis. Logistic regression was performed by a model including factors found significant in univariate analysis. Values with $p<0.05$ or with confidence interval (CI) not including 1.0 were considered statistically significant.

\section{RESULTS}

Mean duration of infection was $11.39 \pm 3.68$ years (range, 3-16 years). In the cases of 22 children (71\%), $\mathrm{HCV}$ infection lasted longer than 10 years. The majority of children were infected by parenteral route $(90 \%)$. Sixty-two percent of children underwent treatment for childhood malignancy in the past. All of these children finished their oncological treatment more than 5 years prior to the study. Ten children were treated because of childhood leukaemia with chemotherapy; nine children had solid tumours and underwent surgical procedures followed by chemotherapy. None of the children required bone marrow transplantation. Histological assessment revealed mild to moderate grading and staging in the liver (Table 1). Twelve children developed fibrotic lesions staged $\mathrm{F} \geq 2$ - eight of them were scored $F 2$, followed by three F3, and one child was scored F4 in histopathological evaluation. Liver steatosis was present in biopsy specimens of 12 children. The proportion of steatosis varied from 0 to $5 \%$. An example histological picture of liver steatosis was presented in Fig. 1.

Table 2 displays clinical, laboratory parameters and APRI in children in relation to liver steatosis. In both groups, no differences were discovered regarding history data and the majority of laboratory parameters including: duration of infection, cholesterol level, HCV-RNA viral load and viral genotype. Children with liver steatosis had higher BMI and ALT activity. These results were, however, not statistically significant. Nevertheless, significantly higher mean AST activity was observed in this group of children, as well as higher APRI index. Marked

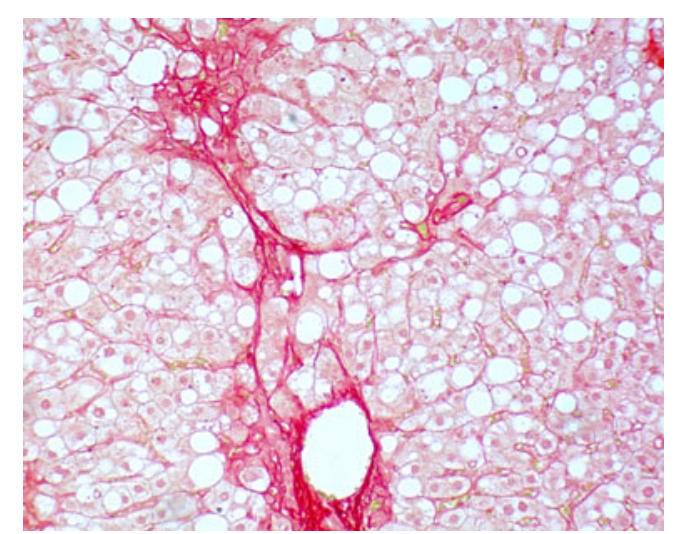

Fig. 1. Chronic hepatitis $\mathrm{C}$ with fibrosis forming short fibrous spurs (stage 2, METAVIR) radiating into the parenchyma from the portal tract (Sirius red staining). There is also focal fatty change. 
Table 2. Clinical and Laboratory Parameters in Children with $\mathrm{CHC}$ with and without Liver Steatosis

\begin{tabular}{|c|c|c|c|}
\hline Parameter & $\begin{array}{l}\text { CHC group with liver steatosis, } n=12 \\
X \pm \mathrm{SD}\end{array}$ & $\begin{array}{l}\text { CHC group without liver steatosis, } n=19 \\
X \pm \mathrm{SD}\end{array}$ & $p$ value \\
\hline Age (years) & $15.25 \pm 1.66$ & $15.00 \pm 2.72$ & 0.77 \\
\hline Gender, $\mathrm{M} / \mathrm{F}$ & $5 / 7$ & $13 / 6$ & 0.13 \\
\hline Age at infection (years) & $3.33 \pm 3.42$ & $3.78 \pm 3.39$ & 0.72 \\
\hline Duration of infection (years) & $11.92 \pm 3.23$ & $11.22 \pm 4.02$ & 0.62 \\
\hline Duration of infection $>10, \mathrm{Y} / \mathrm{N}$ & $10 / 2$ & $12 / 7$ & 0.21 \\
\hline Probable route of infection parenteral/vertical & $10 / 2$ & $18 / 1$ & 0.29 \\
\hline History of paediatric malignancy, $\mathrm{Y} / \mathrm{N}$ & $5 / 7$ & $6 / 13$ & 0.42 \\
\hline Weight $(\mathrm{kg})$ & $62.10 \pm 14.60$ & $59.33 \pm 13.24$ & 0.59 \\
\hline BMI $\left(\mathrm{kg} / \mathrm{m}^{2}\right)$ & $22.55 \pm 4.52$ & $20.18 \pm 2.82$ & 0.08 \\
\hline ALT (IU/l) & $114.17 \pm 140.98$ & $46.83 \pm 33.68$ & 0.06 \\
\hline AST (IU/l) & $82.83 \pm 74.49$ & $35.28 \pm 16.00$ & $0.013 *$ \\
\hline GGTP (IU/l) & $28.08 \pm 74.49$ & $40.78 \pm 12.41$ & 0.53 \\
\hline PLT (g/l) & $237.41 \pm 67.41$ & $236 \pm 57.24$ & 0.95 \\
\hline Cholesterol (mg/dl) & $145.33 \pm 35.36$ & $143.72 \pm 2.89$ & 0.88 \\
\hline HCV-RNA viral load (IU/ml) & $1,672,501 \pm 2,813,650$ & $1,814,378 \pm 3,552,773$ & 0.90 \\
\hline Genotype $1 \mathrm{~b} /$ other & $4 / 8$ & $3 / 16$ & 0.19 \\
\hline Inflammatory activity (METAVIR) & $1.67 \pm 0.78$ & $1.24 \pm 0.44$ & 0.067 \\
\hline Fibrosis (METAVIR) & $1.75 \pm 0.97$ & $1.41 \pm 0.80$ & 0.31 \\
\hline Fibrosis score $\mathrm{F} \geq 2, \mathrm{Y} / \mathrm{N}$ & $6 / 6$ & $13 / 6$ & 0.25 \\
\hline APRI & $1.22 \pm 1.25$ & $0.44 \pm 0.17$ & $0.013^{*}$ \\
\hline
\end{tabular}

$A P R I$ AST-to-platelets ratio index, $Y$ yes, $N$ no, $X$ mean, $S D$ standard deviation, $M$ median $*_{p}<.05$

correlations were found between ALT and AST and proportion of steatosis $(r=0.38$ and $r=0.39$ were appropriate; $p<0.05)$ and BMI and proportion of steatosis $(r=0.55 ; p<0.05)$. As far as histological assessment was concerned, children with coexisting liver steatosis had slightly higher inflammatory activity. The difference was, however, not statistically significant. Furthermore, inflammatory activity correlated to the proportion of steatosis $(r=0.38 ; p<0.05)$. Both groups of children did not differ regarding stage of fibrosis and number of children with fibrosis scored $\mathrm{F} \geq 2$.
WBC was significantly lower in $\mathrm{CHC}$ patients compared to the control group (Table 3). CHC patients had significantly higher MFI of KIR2D than the controls. Expression of remaining receptors was similar in both $\mathrm{CHC}$ patients and controls. NK cell phenotypes differed significantly in children with $\mathrm{CHC}$ in relation to liver steatosis as presented in Table 4. Although the number of NK cells was similar in both groups, children with coexisting liver steatosis had significantly higher mean MFI for CD158e and lower MFI for NKG2D (Fig. 2a-d). The proportion of cells with the expression

Table 3. Expression of Selected Receptors on NK Cells in CHC Patients and in the Control Group

\begin{tabular}{llll}
\hline & Children with CHC $n=31$ & Control group $n=23$ & $p$ value \\
Parameter & $X \pm \operatorname{SD}(M)$ & $X \pm$ SD $(M)$ & $0.0002^{*}$ \\
\hline WBC $(\mathrm{g} / \mathrm{l})$ & $6.54 \pm 2.30(6.11)$ & $8.64 \pm 2.85(7.37)$ & 0.937 \\
NK cells $($ cells $/ \mu \mathrm{l})$ & $345.49 \pm 248.33(252.16)$ & $340.86 \pm 163.73(376.80)$ & 0.741 \\
CD158b expression-proportion of cells (\%) & $30.84 \pm 11.02(26.60)$ & $29.87 \pm 11.18(30.60)$ & 0.367 \\
CD158b MFI & $3,390.16 \pm 1,914.18(2,921.00)$ & $3,390.16 .83 \pm 1,542.52(3,185.00)$ & 0.732 \\
CD158e expression-proportion of cells (\%) & $14.09 \pm 10.82(10.70)$ & $15.16 \pm 13.32(16.20)$ & 0.121 \\
CD158e MFI & $13,575.13 \pm 8,873.98(13,976.00)$ & $9,881.96 \pm 8,907.03(8,454.00)$ & 0.059 \\
KIR2D expression-proportion of cells (\%) & $47.61 \pm 12.28(46.20)$ & $49.35 \pm 13.99(54.50)$ & $0.042 *$ \\
KIR2D MFI & $23,391.82 \pm 6,643.03(21,957.00)$ & $19,040.09 \pm 9,720.62(19,025.00)$ & 0.598 \\
NKG2D expression-proportion of cells (\%) & $96.15 \pm 4.44(97.15)$ & $96.70 \pm 1.81(96.75)$ & 0.564 \\
NKG2D MFI & $4,627.92 \pm 931.47(4,603.00)$ & $4,827.95 \pm 1,402.12(5,326.50)$ &
\end{tabular}

$X$ mean, $S D$ standard deviation, $M$ median

$* p<.05$ 
Table 4. Expression of Selected Receptors on NK Cells in Both Groups of Children with CHC

\begin{tabular}{llll}
\hline & $\begin{array}{l}\text { CHC group with liver steatosis, } n=12 \\
\text { Parameter }\end{array}$ & $\begin{array}{l}\text { CHC group without liver steatosis, } n=19 \\
X \pm \mathrm{SD}(M)\end{array}$ & $p$ value \\
\hline WBC $(\mathrm{g} / \mathrm{l})$ & $6.94 \pm 1.28(6.65)$ & $6.16 \pm 3.08(6.51)$ & 0.415 \\
NK cells $($ cells $/ \mu \mathrm{l})$ & $342.48 \pm 164.81(468.04)$ & $322.53 \pm 263.90(293.70)$ & 0.818 \\
CD158b expression-proportion of cells $(\%)$ & $33.54 \pm 8.86(31.00)$ & $29.35 \pm 13.85(27.65)$ & 0.362 \\
CD158b MFI & $3,725.33 \pm 2,489.77(3,295.50)$ & $3,013.83 \pm 1,482.11(2,732.00)$ & 0.334 \\
CD158e expression-proportion of cells (\%) & $17.55 \pm 12.06(10.60)$ & $11.67 \pm 9.09(14.40)$ & 0.139 \\
CD158e MFI & $18,815.92 \pm 7,075.30(17,869.50)$ & $9,656.00 \pm 8,087.91(8,952)$ & $0.003 *$ \\
KIR2D expression-proportion of cells $(\%)$ & $53.35 \pm 12.28(50.85)$ & $43.56 \pm 13.99(45.50)$ & 0.059 \\
KIR2D MFI & $24,284.00 \pm 7,061.97(21,724.00)$ & $21,813.00 \pm 5,171.90(21,595.00)$ & 0.277 \\
NKG2D expression-proportion of cells $(\%)$ & $97.86 \pm 1.32(97.15)$ & $94.45 \pm 6.59(96.95)$ & 0.125 \\
NKG2D MFI & $4,117.22 \pm 360.95(4,261.00)$ & $5,104.67 \pm 1,058.38(5,321.00)$ & $0.018^{*}$ \\
\hline
\end{tabular}

$W B C$ white blood cells, $N K$ natural killer, $M F I$ mean fluorescence intensity, $X$ mean, $S D$ standard deviation, $M$ median ${ }^{*} p<.05$

of these receptors as well as the remaining ones and their MFI did not differ in both groups of children with CHC.
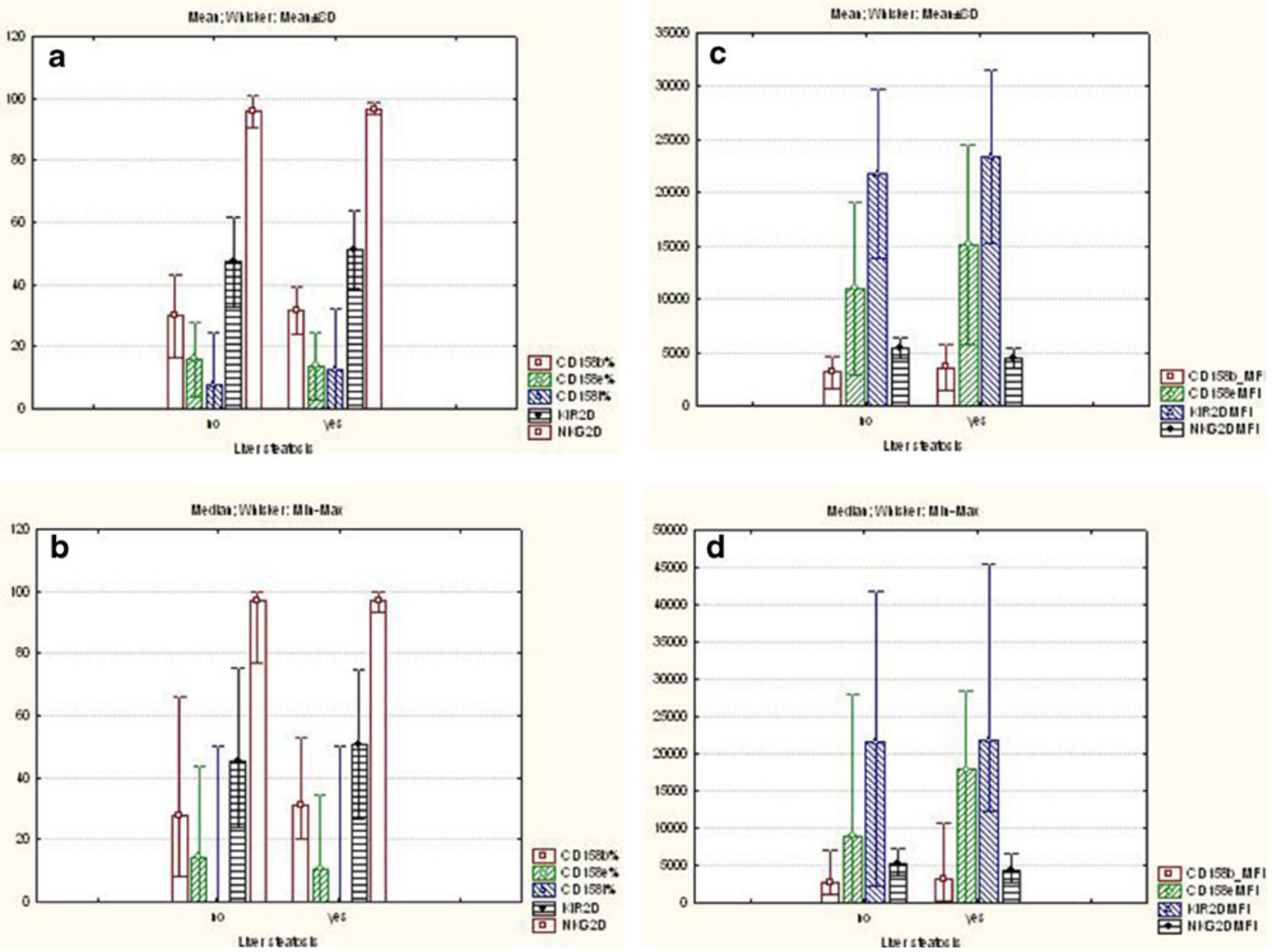
Fig. 2. Mean (a) and median (b) of proportion of cells with expression of selected NK cell receptors and fluorescence intensity (c, d) in children with chronic hepatitis $\mathrm{C}$ with and without liver steatosis.

Example pictures from flow cytometry were presented in Fig. 3. The proportion of cells expressing CD158i,

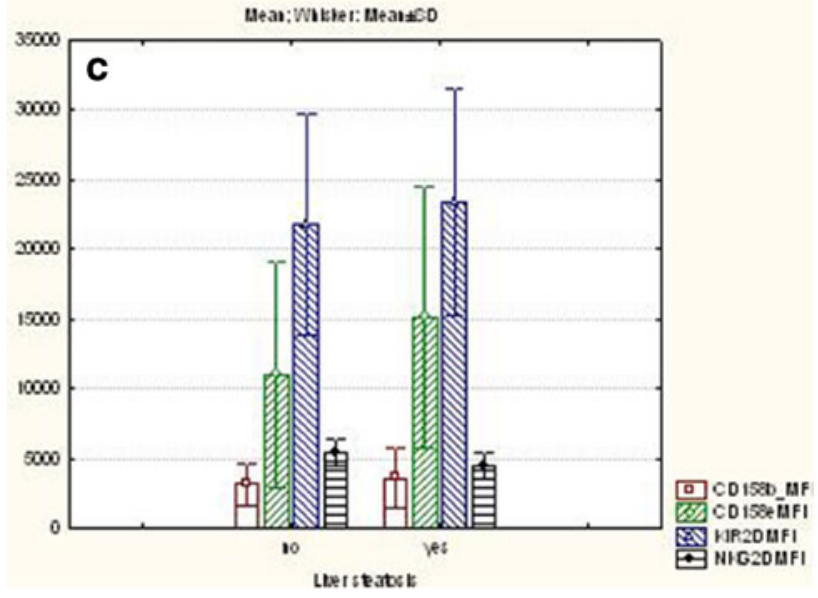

2 CD ISe IAFI VIR2DIAFI 

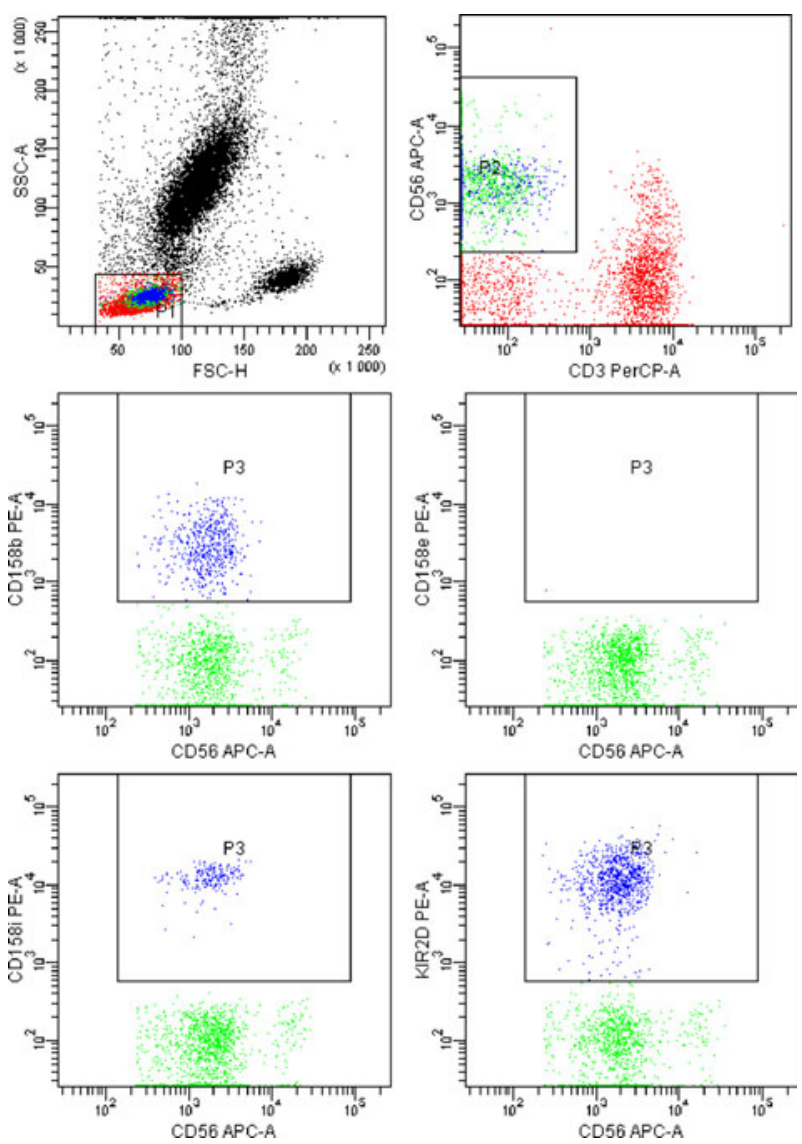

Fig. 3. Flow cytometry diagnostic approach—example pictures for specific NK cell antibodies.

KIR2D and NKG2D was inversely related to the age of patients $(r=-0.72, r=-0.68, r=-0.49$, were appropriate; $p<0.05)$. Moreover, MFI of CD158b correlated to the age at infection $(r=0.53)$. Expression of CD158e and CD158i proportional to aminotransferase activity-ALT $(r=0.55$ and $r=0.58$, were appropriate, $p<0.05)$ and AST $(r=0.53$ and $r=0.55$, were appropriate, $p<0.05)$. MFI of CD $158 \mathrm{e}$ was directly related to the proportion of steatosis $(r=0.64, p<0.05)$.

Factors associated with the presence of liver steatosis were sought using univariate analysis. Presence of steatosis was not associated with age, age at infection and duration of infection. In univariate analysis, the proportions of cells with expression of CD158i, KIR2D, BMI and APRI were found to be independent predictors of liver steatosis. The presence of liver steatosis was more probable with an increase of CD 158i and KIR2D expression as well as rise in BMI and APRI value. Moreover, it was more credible with a rise of BMI and 6.62 times more probable with an increase of the APRI index. Parameters that were found statistically significant in univariate analysis were included in logistic regression model, and only BMI remained significant. An increase of BMI made liver steatosis 1.43 times more probable. Results of univariate analysis and logistic regression were presented in Table 5.

\section{DISCUSSION}

Mechanisms underlying liver steatosis in $\mathrm{CHC}$ have been proved to be genotype specific. Fatty liver is more commonly related to genotype 3 , while genotype 1 was associated with insulin resistance. HCV affects biosynthesis of fatty acids by enhancing the expression of several enzymes involved in the process. It also influences the assembly and secretion of triglycerides. Moreover, HCV core protein causes mitochondrial injury and oxidative stress altering lipid peroxidation [9, 10]. Metabolic syndrome is seen less frequently in $\mathrm{CHC}$ patients 
Table 5. Factors Associated with the Presence of Liver Steatosis in Children with $\mathrm{CHC}$

\begin{tabular}{|c|c|c|c|c|}
\hline \multirow[b]{2}{*}{ Predictor } & \multicolumn{2}{|l|}{ Univariate analysis } & \multicolumn{2}{|l|}{ Logistic regression } \\
\hline & OR $(95 \% \mathrm{CI})$ & $p$ & OR $(95 \% \mathrm{CI})$ & $p$ \\
\hline Age (years) & $1.097(0.78-1.53)$ & 0.56 & - & - \\
\hline Age at infection (years) & $0.96(0.76-1.22)$ & 0.77 & - & - \\
\hline Duration of infection (years) & $1.07(0.8-1.33)$ & 0.52 & - & \\
\hline AST (IU/1) & $1.03(0.99-1.07)$ & 0.09 & - & - \\
\hline Expression of CD158b-proportion of cells (\%) & $1.03(0.96-1.10)$ & 0.34 & - & - \\
\hline CD158b MFI & $1.00(0.99-1.00)$ & 0.92 & - & \\
\hline Expression of CD158e - proportion of cells (\%) & $1.05(0.97-1.13)$ & 0.19 & - & - \\
\hline CD158e MFI & $0.99(0.98-1.00)$ & 0.69 & - & \\
\hline Expression of CD158i-proportion of cells (\%) & $1.04(0.99-1.08)$ & $0.048^{*}$ & $1.01(0.93-1.09)$ & 0.81 \\
\hline CD158i MFI & $1.11(0.78-1.12)$ & 0.99 & - & \\
\hline Expression of KIR2D - proportion of cells (\%) & $1.06(0.99-1.12)$ & $0.049^{*}$ & $1.05(0.96-1.16)$ & 0.26 \\
\hline KIR2D MFI & $1.07(0.98-1.24)$ & 0.78 & - & \\
\hline Expression of NKG2D - proportion of cells (\%) & $1.31(0.83-2.05)$ & 0.22 & - & - \\
\hline NKG2D MFI & $1.00(0.99-1.01)$ & 0.96 & - & \\
\hline Inflammatory activity (METAVIR) & $3.35(0.8-13.96)$ & 0.08 & - & - \\
\hline Fibrosis (METAVIR) & $1.59(0.62-4.08)$ & 0.304 & - & - \\
\hline BMI $\left(\mathrm{kg} / \mathrm{m}^{2}\right)$ & $1.23(0.97-1.56)$ & $0.047 *$ & $1.43(1.01-2.03)$ & $0.04 *$ \\
\hline APRI [(AST (IU/l)/UNL (IU/l)/PLT $(\mathrm{g} / \mathrm{l})) \times 100]$ & $6.62(0.54-80.08)$ & $0.006^{*}$ & $14.8(0.35-630)$ & 0.14 \\
\hline
\end{tabular}

compared to non-alcoholic fatty liver disease individuals [11]. Nevertheless, liver steatosis accelerates the progression of liver fibrosis in CHC patients [12]. In the current study, the majority of patients were infected with genotype 1 (all but one patient); therefore, any genotype-related differences could not be performed. No difference was observed in the frequency of liver steatosis between genotype $1 \mathrm{~b}$ and non- $1 \mathrm{~b}$ infected patients.

As a significant proportion of patients were treated for paediatric malignancy in the past, the study included patients who had finished oncological treatment at least 5 years prior to the study to avoid the influence of medications used. Thus, steatosis was observed with similar frequency among patients with and without oncological history. Presence of steatosis was associated with higher AST and APRI level - a non-invasive marker of liver fibrosis. Since a higher APRI level was described to be associated with advanced fibrosis [13], a potential link with increased level of this marker and steatosis (also a predictor of liver damage) is understandable. Higher ALT activity and BMI was also seen in the group of children with steatosis, although the results were not statistically significant. Thus, both ALT and AST activities were related to the proportion of cells with steatosis. Furthermore, existing reports show that presence of steatosis is related to higher BMI of patients. Increased fat intake results in accumulation of fatty tissue and a rise in patient weight. Moreover, an increase in baseline BMI significantly reduces the proba- bility of sustained virological response in paediatric patients with CHC [14]. In the current study, BMI was found to be a predictor of steatosis in a logistic regression model.

Although in the current study no difference regarding liver fibrosis was found between the group of $\mathrm{CHC}$ children with and without coexisting steatosis, further progression of fibrotic lesions with time may be difficult to predict. Liver fibrosis is a slow process that may be aggravated by additional factors, and steatosis is one of them. Hepatic fibrogenesis has been shown to be affected by NK cell activation through the release of interferon gamma (IFN- $\gamma$ ), IFN- $\alpha$ or dsRNA. IFN- $\gamma$ attenuation of liver fibrosis occurs also through the direct killing of activated HSCs [7]. The number of NK cells was found to be altered in $\mathrm{CHC}$ patients leading to lack of control on HSCs and increased fibrogenesis. Steatosis may also decrease the number of hepatic NK cells by determining an alteration in cytokine homeostasis with an amplified release of pro-inflammatory cytokines. Inverse correlation between the severity of liver steatosis and NK cell number in animal models was revealed [15]. In the current study, however, not the number but the expression of NK cell receptors was altered. The phenotype of NK cells varied between $\mathrm{CHC}$ patients and controls in terms of higher KIR2D expression in the first group. Moreover, MFI of CD158e was significantly higher, and NKG2D was lower in $\mathrm{CHC}$ children with coexisting steatosis. Thus, the proportion of cells with expression of CD158e was also 
higher in CHC children with coexisting liver steatosis, and the proportion of cells with NKG2D expression did not differ significantly between the groups. MFI reflects intensity of the expression of receptors which is independent from the number of cells; therefore, the differences in MFI may not be reflected in the number of cells with the expression of certain receptors. This phenomenon may explain lack of significance in the proportion of cells expressing analysed receptors with coexisting significant differences regarding their MFI.

Furthermore, univariate analysis showed a relation between the presence of fibrosis and other NK cell receptors-activating CD $158 \mathrm{i}$ and inhibitory KIR2D. Expression of these receptors was also higher in children with fatty liver in a simple comparison; the difference was, however, not statistically significant. Expression of the inhibitory CD158e was higher in the presence of steatosis, while the expression of activating NKG2D was lower in the same situation. Inhibitory phenotype of NK cells could be associated with a higher level of liver injury. NK cells initiate apoptosis of activated HSC or are able to kill them directly; therefore, their inhibition prevents limitation of HSC activity. On the other hand, an inhibitory phenotype of NK cells could result in more advanced liver steatosis. Lower expression of NKG2D in CHC patients could be related to the fact that $\mathrm{HCV}$ down-regulates a ligand for this receptor-MHC class I -related chain type A [16]. Furthermore NKG2D expression may be down-regulated by TGF-beta, a pro-inflammatory cytokine released by Kupffer cells and HSC [17]. Nevertheless, significance of these parameters were not confirmed by univariate analysis, which revealed that a rise in the proportion of cells with the expression of activating receptor CD158i and KIR2D may be related to the presence of liver steatosis. Thus, logistic regression did not prove these findings. In the latter analysis, only BMI of the patients was associated with liver steatosis.

An inverse relation existed between age of the patients and the proportion of NK cells expressing activating receptors CD158i and NKG2D. Moreover, MFI of inhibitory receptor CD158b was correlated to the age of $\mathrm{CHC}$ children. This phenomenon could explain agerelated differences in the course of $\mathrm{CHC}$. NK cells seem to display more activating phenotype in the younger age; therefore, liver injury is at the lower stage in younger patients. Probably with the duration of infection inhibitory receptors are expressed in greater extent and therefore NK cells have smaller potential to inhibit the process of the liver injury. This finding, however, requires further studies on a larger group of children and adults with $\mathrm{CHC}$.
Although not significant, children with steatosis had slightly higher inflammatory activity in the Mann-Whitney test. Inflammatory activity was, however, balanced to the proportion of cells with steatosis. Furthermore, inflammatory activity as a predictor of liver steatosis showed borderline significance. In the setting of steatosis, inflammatory response may be modulated by fatty acids and their metabolites. Furthermore, activation of immune pathways can adversely affect hepatic lipid metabolism leading to liver injury, steatohepatitis and fibrosis. Activation of the immune system in the condition of steatosis causes increased hepatic production of TNF- $\alpha$, Il-12 and IFN- $\gamma$, factors that either activate or stimulate apoptosis of NK cells. Activation of NK cells results in the inhibition of liver fibrosis and steatosis down-regulates NK cells. Therefore, the presence of steatosis may accelerate the progression of liver fibrosis. On the other hand, intrahepatic NK cell cytotoxic function is impaired in patients with $\mathrm{CHC}$ [4]. The exact intercourse between these processes is probably more complex than we are currently aware and requires further studies to elucidate cause-effect relations.

In clinical terms, it has been observed that NK cell activity is negatively correlated with liver fibrosis in patients with HCV infection. Further studies will be required to confirm whether stimulating NK cell activity is effective and safe in treating human liver fibrosis. Moreover, expression of certain NK cell receptors has been proven to be related to the results of treatment in $\mathrm{CHC}[18,19]$.

\section{ACKNOWLEDGMENTS}

The study was supported by a research grant of the Polish Ministry of Science and Higher education - grant no NN 407012036 (to A. Mania) and NN 401535740 (to I. Mozer-Lisewska).

Open Access This article is distributed under the terms of the Creative Commons Attribution License which permits any use, distribution, and reproduction in any medium, provided the original author(s) and the source are credited.

\section{REFERENCES}

1. Mania, A., P. Kemnitz, M. Figlerowicz, I. Mozer-Lisewska, A. Kowala-Piaskowska, A. Woźniak, and W. Służewski. 2012. Clinical picture and liver histology of chronic hepatitis $\mathrm{C}$ in children. Infectious Diseases in Clinical Practice 20: 141-147. 
2. Moretta, L., G. Ferlazzo, C. Bottino, M. Vitale, D. Pende, M.C. Mingari, and A. Moretta. 2006. Effector and regulatory events during natural killer-dendritic cell interactions. Immunology Reviews 214: 219-228.

3. Doherty, D.G., S. Norris, L. Madrigal-Estebas, G. McEntee, O. Traynor, J.E. Hegarty, and C. O'Farrelly. 1999. The human liver contains multiple populations of NK cells, T cells, and $\mathrm{CD} 3+\mathrm{CD} 56+$ natural T cells with distinct cytotoxic activities and Th1, Th2, and Th0 cytokine secretion patterns. Journal of Immunology 163: 2314-2321.

4. Varchetta, S., D. Mele, S. Mantovani, B. Oliviero, E. Cremonesi, S. Ludovisi, G. Michelone, M. Alesani, R. Rosati, M. Montorsi, and M.U. Mondelli. 2012. Impaired intrahepatic natural killer cell cytotoxic function in chronic hepatitis $\mathrm{C}$ virus infection. Hepatology 56: 841-9.

5. Bauer, S., V. Groh, J. Wu, A. Steinle, J.H. Phillips, L.L. Lanier, and T. Spies. 1999. Activation of NK cells and T cells by NKG2D, a receptor for stress-inducible MICA. Science 285: 727-729.

6. Oliviero, B., S. Varchetta, E. Paudice, G. Michelone, M. Zaramella, D. Mavillo, F. De Filippi, S. Bruno, and M.U. Mondelli. 2009. Natural killer cell functional dichotomy in chronic hepatitis B and chronic hepatitis C virus infections. Gastroenterology 137: 1151-1160.

7. Radaeva, S., R. Sun, B. Jaruga, V.T. Nguyen, Z. Tian, and B. Gao. 2006. Natural killer cells ameliorate liver fibrosis by killing activated stellate cells in NKG2D-dependent and tumor necrosisfactor related apoptosis-inducing ligand-dependent manners. Gastroenterology 130: 435-452.

8. Livingstone, S.E., H. Deubner, D.L. Burden, B.J. McMahon, C.E. Homan, L.J. Townshend-Bulson, M.G. Bruce, T.W. Hennessy, J.L. Wiliams, and D.R. Gretch. 2010. Factors associated with the progression of fibrosis on liver biopsy in Alaska Native and American Indian persons with chronic hepatitis C. Canadian Journal of Gastroenterology 24: 445-451.

9. Fukasawa, M., Y. Tanaka, S. Sato, Y. Ono, Y. Nitahara-Kasahara, T. Suzuki, T. Miyamura, K. Hanada, and M. Nishijima. 2006. Enhancement of de novo fatty acid biosynthesis in hepatic cell line Huh7 expressing hepatitis $\mathrm{C}$ virus core protein. Biological and Pharmaceutical Bulletin 29: 1958-1961.

10. Okuda, M., K. Li, M.R. Beard, L.A. Showalter, F. Scholle, S.M. Lemon, and S.A. Weinman. 2002. Mitochondrial injury, oxidative stress, and antioxidant gene expression are induced by hepatitis C virus core protein. Gastroenterology 122: 366-375.

11. Lonardo, A., S. Ballestri, L.E. Adinolfi, E. Violi, L. Carulli, S. Lombardini, F. Scaglioni, M. Ricchi, G. Ruggiero, and P. Loria. 2009. Hepatitis C virus infected patients are 'spared' from the metabolic syndrome but not from insulin resistance. A comparative study of nonalcoholic fatty liver disease and hepatitis $\mathrm{C}$ virus-related steatosis. Canadian Journal of Gastroenterology 23(4): 273-278.

12. Adinolfi, L.E., M. Gambardella, A. Andreana, M.F. Tripodi, R. Utili, and G. Ruggiero. 2001. Steatosis accelerates the progression of liver damage of chronic hepatitis $\mathrm{C}$ patients and correlates with specific HCV genotype and visceral obesity. Hepatology 33: 13581364.

13. Wai, C.T., J.K. Greenson, R.J. Fontana, J.D. Kalbfleisch, J.A. Marrero, H.S. Conjeevaram, and A.S. Lok. 2003. A simple noninvasive index can predict both significant fibrosis and cirrhosis in patients with chronic hepatitis C. Hepatology 38: 518-526.

14. Delgado-Borrego, A., D. Healey, B. Negre, M. Christofi, S. Sabharwal, D.A. Ludwiga, T. Raymond, R.T. Chung, and M.M. Jonas. 2010. The influence of body mass index on outcome of pediatric chronic hepatitis C virus infection. Journal of Pediatric Gastroenterology and Nutrition 51: 191-197.

15. Kremer, M., I.N. Hines, R.J. Milton, and M.D. Wheeler. 2006. Favored T helper 1 response in a mouse model of hepatosteatosis is associated with enhanced T cell-mediated hepatitis. Hepatology 44: 216-227.

16. Wen, C., X. He, H. Ma, N. Hou, C. Wei, T. Song, Y. Zhang, L. Sun, Q. Ma, and H. Zhong. 2008. Hepatitis C virus infection downregulates the ligands of the activating receptor NKG2D. Cellular \& Molecular Immunology 5: 475-478.

17. Castriconi, R., C. Cantoni, M. Della Chiesa, M. Vitale, E. Marcenaro, R. Conte, R. Biassoni, C. Bottino, L. Moretta, and A. Morreta. 2003. Transforming growth factor beta1 inhibits expression of NKp30 and NKG2D receptors: consequences for the NKmediated killing of dendritic cells. Proceedings of the National Academy of Science of the Unite States of America 100: 41204125.

18. Suppiah, V., S. Gauderi, N.J. Armstrong, K.S. O'Connor, T. Berg, M. Weltman, M.L. Abate, U. Spengler, M. Bassedine, G.J. Dore, W.L. Irving, E. Powell, M. Hellard, S. Riodan, G. Matthews, D. Sheridan, J. Natterman, A. Smedile, T. Muller, E. Hammond, D. Dunn, F. Negro, P.Y. Bochud, S. Mallal, G. Ahlenstiel, G.J. Stewart, J. George, D.R. Booth, and International Hepatitis C Genetics Consortium (IHCGC). 2011. IL28B, HLA-C, and KIR variants additively predict response to therapy in chronic hepatitis $\mathrm{C}$ virus infection in a European Cohort: a cross-sectional study. PLoS Med. 8: e1001092.

19. Golden-Mason, L., K.M. Bambha, L. Cheng, C.D. Howell, M.W. Taylor, P.J. Clark, N. Afidhal, H.R. Rosen, and Virahep-C Study Group. 2011. Natural killer inhibitory receptor expression associated with treatment failure and interleukin-28B genotype in patients with chronic hepatitis C. Hepatology 54: 1559-1569. 